\title{
CINCO TENSORES DE CURVATURA. UNA APROXIMACIÓN A LA TOPOLOGÍA ESPACIO-TEMPORAL CONTEMPORÁNEA
}

\section{FIVE CONTEMPORARY CURVATURE}

\section{TENSORS. AN APPROACH TO A NEW}

\section{TEMPORAL SPACE TOPOLOGY}

DOI: https://doi.org/10.18861/ania.2019.9.2924

Arq. Mariágeles Longo

ORCID: https://orcid.org/0000-0001-6703-7586

Arq. Irene Ríos

ORCID: https://orcid.org/0000-0002-8170-1479 


\section{ARQ. MARIÁNGELES LONGO}

Arquitecta. Universidad ORT Uruguay. Actividad profesional Independiente.

\section{ARQ. IRENE RÍOS}

Arquitecta. Universidad ORT Uruguay. Actividad profesional Independiente.

FECHA DE RECEPCIÓN: 1 de setiembre de 2019.

FECHA DE ACEPTACIÓN: 23 de diciembre de 2019.

REGISTRO BIBLIOGRÁFICO: LONGO, M.; RÍOS, I. (2019). Cinco tensores de curvatura. Una aproximación a la topología espacio-temporal contemporánea. Anales de Investigación en Arquitectura, Vol. 9 (2), 89-108.

Artículo basado en la Memoria Fin de Carrera, Facultad de Arquitectura, Universidad ORT Uruguay, 2019: "Estrategias programáticas. Del alojamiento de funciones a la construcción de relaciones". 


\section{RESUMEN}

La cultura contemporánea se identifica con sus propias formas de producción y reproducción del espacio. Un proyecto absolutamente visual de dimensión imaginaria. Lo que aquí se busca exponer es la emergencia de una nueva topología espacio temporal a través del análisis de ciertas estrategias proyectuales cuyas formas y estructuras organizativas se redefinen lógica y tácticamente para comprender las dinámicas complejas del mundo contemporáneo.

A través de cinco estrategias proyectuales concretas, "Cinco Tensores de Curvatura Contemporáneos", se irá trazando una lectura transversal que introduce modelos y discursos provenientes del campo de la sociología y la arquitectura. Los tensores de curvatura denominados así por el sociólogo Luis Castro Nogueira en el libro "La risa del espacio" (1997), hacen referencia a prácticas materiales cuyos códigos visuales pliegan y tensan lo que fue el primer momento espacial moderno.

Todo este proceso de gradación espacial concluye en el espacio virtual. Una tipicidad sintética y simulada por dispositivos electrónicos en la que sujeto, objeto y medio devienen en una progresiva condición inmaterial. Lejos de establecer modelos absolutos estos desplazamientos topológicos buscan instaurar una actitud crítica necesaria para proyectarse hacia futuros escenarios.

Palabras Clave: Espacio, topología, estrategias, arquitectura contemporánea.

\section{RESUMO}

Contemporary culture is identified with its own forms of production and reproduction of space. An absolutely visual project of imaginary dimension. What is mean to be expose is the emergence of a new temporal space topology, through the analysis of certain project strategies whose organizational forms and structures are logically and tactically redefined to understand the complex dynamics of the contemporary world.

Through five concrete project strategies, "Five contemporary curvature tensors", a transversal reading that introduces models and discourses from the field of sociology and architecture will be drawn. The curvature tensors named by the sociologist Luis Castro Nogueira in the book "Laughter of space" (1997), refer to material practices whose visual codes fold and tense the first modern space moment as it is known.

This whole process of spatial gradation concludes in the virtual space. A synthetic and simulated typicity by electronic devices in which subject, object and medium become a progressive immaterial condition. Far from establishing absolute models, these topological displacements seek to establish a critical attitude necessary to project into future scenarios.

Keywords: Space, topology, strategies, contemporary architecture. 


\section{INTRODUCCIÓN}

La sociedad de la información ha desenvuelto su propio aparato conceptual. Tal como sostiene Luis Castro Nogueira en el libro "La risa del espacio" (1997), el espacio/tiempo social de la cultura contemporánea parecen declinarse hacia un sentido espacial más que temporal. Este mundo "hiperreal” se desenvuelve en un espacio dual, conformado por una dimensión material y otra conceptual. Esta última es la que adquiere espesor imaginario.

La crisis de los paradigmas científicos y la incidencia de los avances tecnológicos, desencadenaron en una profunda restructuración del conocimiento y de las prácticas sociales. Como consecuencia, los métodos de trasmisión de información avanzados modificaron ampliamente las estructuras de pensamiento y de producción económica.

Ante la hipótesis de que la noción de espacio social está adquiriendo cada vez mayor protagonismo, la arquitectura como registro material de la relación hombre-mundo materializa una idea de espacio acorde a dicha coyuntura. Bajo esta perspectiva, se definen cinco posibles estrategias proyectuales, "Cinco tensores de curvatura contemporáneos”, cuyos régimenes escópicos de visualidad resitúan al individuo en el espacio.
Como vector espacial, el tiempo, es el coeficiente que provoca las múltiples deformaciones. Es un hecho constatado que la aceleración del mismo ha generado un progresivo desgaste de las cualidades cohesivas y autosuficientes que presentaba la estructura tipológica. El observador moderno productor de la experiencia espacial pierde peso en estos contextos signados por flujos temporales de información. En el pasado, tiempo e historia eran sinónimos de estabilidad. Ahora se desestabilizan en la instantaneidad y simultaneidad de los hechos.

Por otra parte, el cuerpo de las imágenes alcanza hoy niveles de complejidad conceptual que subordinan el dominio del hombre. La velocidad y la capacidad persuasiva les otorgan motus propio. El espacio euclídeo que admitía decodificarse y visualizarse, adquiere múltiples dimensiones superpuestas que complejizan su abordaje. Analizarlo implica interpretar cada uno de estos estratos por separado. Se trata de capas de información con distintas temporalidades asociadas, que necesitan ser sintetizadas en unidades mínimas para poder ser trasladadas al proyecto arquitectónico (Gausa, 2010).

Entonces, la aceleración del tiempo genera que las imágenes se "despeguen" del sujeto y circulen a velocidades inconmensurables. Por otra parte, sus nuevas funciones adquiridas (consistencia, autenticidad y durabilidad) las convierten en constructos de potencial imaginario. Es decir, adquieren la capacidad de incidir persuasivamente sobre los usuarios. 


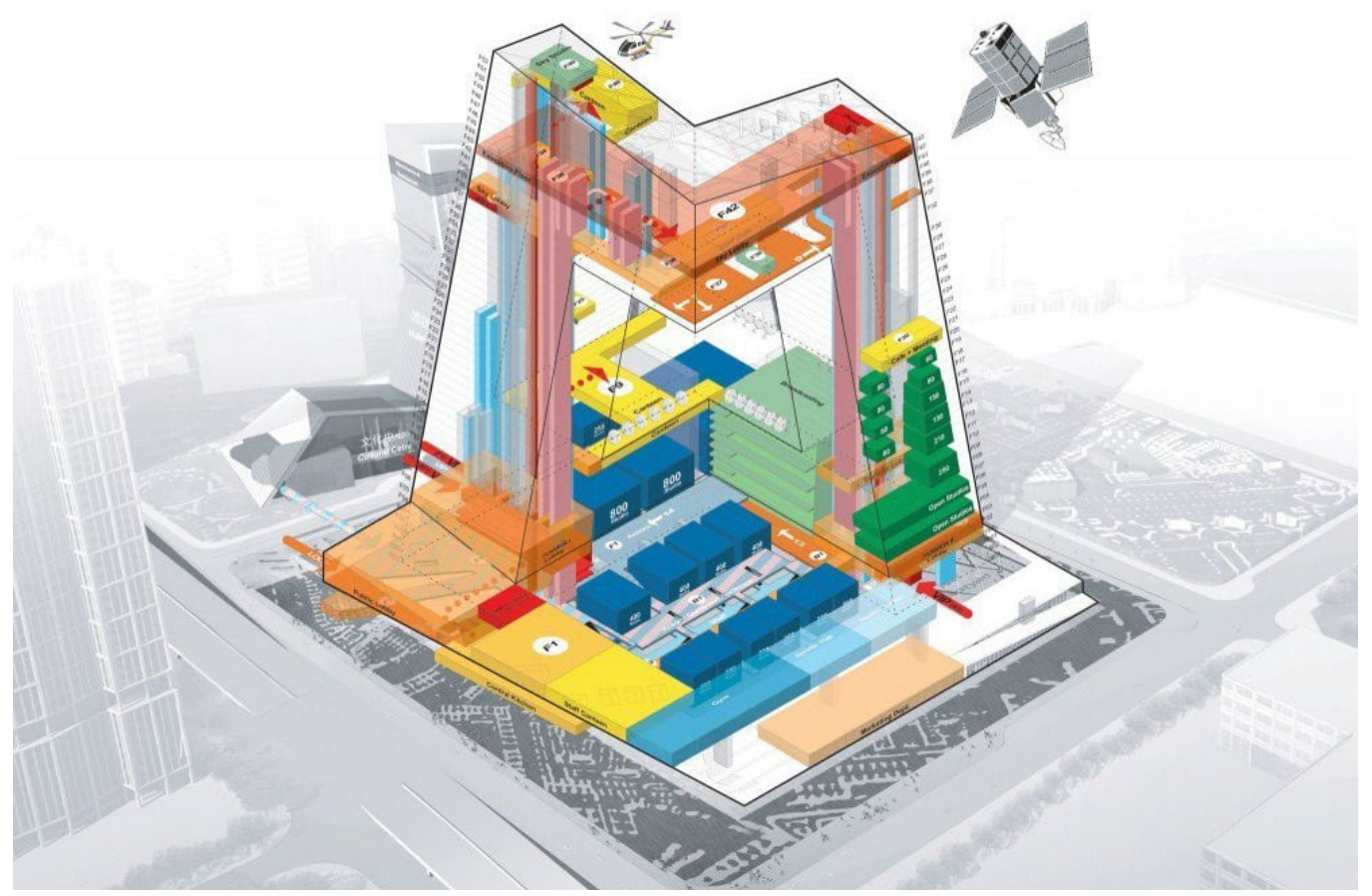

Figura 1.

Axonométrica del edificio CCTV OMA (2012).

En este sentido, las formas y soportes organizativos se redefinen lógica y tácticamente en función de la información que procesan. Los vínculos que se tejen entre las partes impulsan, desarrollan y combinan acciones y efectos reactivos e interactivos con la realidad. La cartografía contemporánea materializa un espacio que se representa por lo que es, por su carácter performativo. Lo cual implica un cambio de pensamiento y de proceder. La capacidad de uso se superpone sobre el plano conceptual.
Frente a un mundo complejo, la posible emergencia de una nueva topología espacio temporal estriba diversas maneras de ver $y$ entender el proyectar contemporáneo. Los sistemas dinámicos perturban las estructuras y ordenes de antaño. Esta progresiva "tensión" da como resultado geometrías complejas (polimórficas, poliédricas) cuyas trayectorias se asocian a soportes de carácter infraestructural más que estructural. Se trata de pseudo-estructuras que operan por medio de interconexiones flexibles alcanzando un alto grado de azar y complejidad. 
Dichos comportamientos se vinculan con modelos formales-figurativos procedentes del campo de la sociología, descriptivos de una imagen de mundo caótico y multidimensional. Como es el caso del rizoma, presentado por Ios filósofos Deleuze y Guattari en el libro "Mil Mesetas. Capitalismo y esquizofrenia” (2002). El rizoma representa un sistema abierto de interacciones ramificadas de manera aleatoria, sin centro ni jerarquías. La articulación de fuerzas va variando alterando las reglas para comprender el caos dentro de un todo. De este modo, las fragmentaciones y conexiones se pueden dar en cualquier parte de la estructura provocando mayor variabilidad de acontecimientos.

Desde 1960 el modelo de producción económica, el capitalismo avanzado, ha desenvuelto una forma de organización del espacio urbano que se materializa en una topografía discontinua. José Morales en el artículo "Adios a la metáfora. Manipulaciones de la realidad" (2010) manifiesta que la propia "realidad texturada" es la que mantiene el equilibrio y especificidad del orden superior. El potencial del hecho arquitectónico reside en su carácter inflexivo. Según el sociólogo Zygmunt Bauman (2000), el modus operandi de la "economía líquida" se basa en la continua circulación del capital, en continuos desplazamientos espacio-temporales que domestican y reorganizan el territorio. No opera por expansión sino a través de la generación de espacios virtuales mediados por plataformas de comunicación. De esta forma, las barreras espaciales se desintegran. La trama consigue ser maleada facilitando desplazamientos extensivos a través de centralidades con capacidad de producción e intercambio.

Este giro espacial esboza una profunda reorganización del territorio. A la trama tradicional se le superpone el espacio global que asegura su rendimiento en la especificidad de lo local. Es decir, en las topografías sintéticas con suficiente capacidad crítica para competir por el territorio.

No cabe duda que la información ha alcanzado un grado tal de infiltración que ha permeado la esfera de lo social, cultural y hasta los propios procesos naturales. Filósofos como Mark C.Taylor (2003), manifiestan que es necesaria la emergencia de nuevos modelos críticos que eviten la capitalización de la arquitectura (Tschumi, Cheng, 2003). Es en los modelos contemporáneos "constructores" de ciudad: "alfombras operativas", híbridos, redes y mallas rizomáticas, donde se instaura la dicotomía entre lo crítico y lo global.

\section{CINCO TENSORES DE CURVATURA CONTEMPORÁNEOS:}

Los tensores de curvatura vienen a ser, siguiendo la perspectiva que sostiene Luis Castro Nogueira en el libro "La risa del espacio" (1997), las deformaciones n-dimensionales que suceden en el espacio-tiempo social de una 


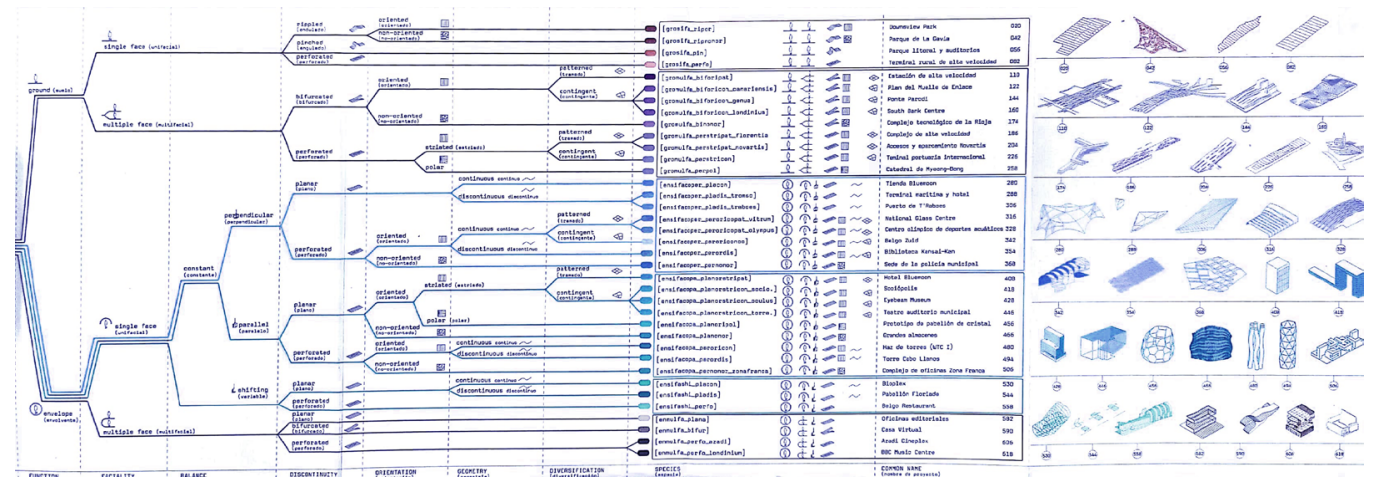

Figura 2.

El árbol de los arquitectos Zaera-Polo y Moussavi en "Phylogenesis FOA's Ask" (1999)

Las exploraciones teóricas llevadas a cabo por el estudio de arquitectos FOA toman referencias directas del campo de la biología. Presenta el concepto de especie como contrapunto a la noción tradicional de tipología. Las especies trabajan operativamente por medio de relaciones morfológicas que varían en el tiempo y en el espacio, adaptándose a los cambios. Adquieren de esta forma un grado de elasticidad que les permite crecer en múltiples ecosistemas.

determinada época. Dichas asimetrías estriban el nacimiento de ciertas alteraciones materiales cuyos códigos visuales pliegan y tensan el espacio arquitectónico.

Se definen cinco posturas proyectuales concretas para abordar dicha coyuntura: "Indeterminaciones en el espacio genérico", "Patrones de equivalencia programática", "Espacios híbridos multiprogramados", “El pliegue programático" y “Licuaciones programáticas en el espacio virtual".

Se trata de estrategias cuyas lógicas internas perturban las estructuras y ordenes de antaño, desterritorializando órdenes y funciones prestablecidas. Según Stan Allen (1999), en la actualidad persiste una mayor preocupación por la capacidad de la arquitectura de "hacer" por encima de representar. El "nuevo pragmatismo" tal como lo denomina John Rajchman (1997), concibe la arquitectura como receptáculo de efectos e intercambios. La teoría y práctica se alinean y se resignifican. Lo disciplinar se "desacraliza" dejando de postularse como representación y significado, en su lugar se propone una lectura alterna direccionada a la producción de efectos (García-German, 2012).

Una de las posibles razones que explica este viraje performativo se alinea con el cambio de paradigma imbuido por las ciencias naturales. La "revolución genética" ha abierto un abanico de estrategias proyectuales con lógicas asimilables a los procesos biológicos. Se programan reglas básicas con capacidad evolutiva que permiten alcanzar un alto grado de azar y complejidad. Siguiendo la perspectiva que se sostiene Gausa 

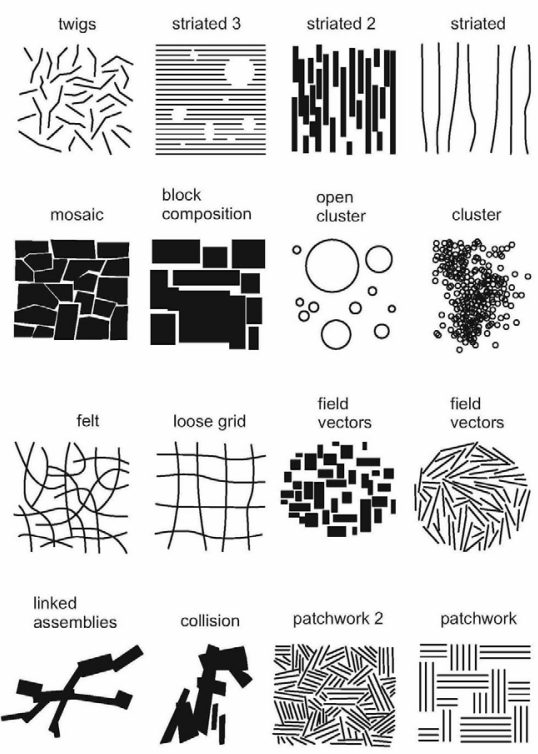

Figura 3.

Field Conditions.

Las "condiciones de campo" refieren a dinámicas de carácter no-lineal que hacen visibles las fuerzas abstractas latentes en el espacio: funciones, vectores y velocidades en el "Diccionario Metápolis de Arquitectura Avanzada" (2001) se trata de un orden "informal". El mismo implica una triple inyectiva: reacción ante la información, no-formas o forma informe y códigos que no guardan vínculos con comportamientos predeterminados.

Los procesos formales dejan de subordinarse a un marco de referencia absoluto que frena las transformaciones. La adherencia que presentaba la estructura tipológica no permitía absorber los cambios sin alterar su integridad. Se pasa del orden reproductivo composicional de base planimétrica a un orden "elástico". Los procesos que se generan son mucho más complejos, involucran mecanismo de progresiva hibridación, discontinuidad-conectividad, pliegues y repliegues programáticos provocados por la acción de fuerzas espaciales. (Gausa, 2010).

Los dos primeros tensores: "Indeterminaciones en el espacio genérico" y "Patrones de equivalencia programática" son de carácter preliminar. Redefinen mecanismos organizativos heredados de la modernidad.

Al respecto la postura contemporánea relativiza el concepto de espacio genérico. Las "Indeterminaciones en el espacio genérico" plantean ciertas distorsiones sobre los soportes neutros, como la planta libre. Las cuales buscan abrir el espacio genérico a la individualidad y diversidad. La iteración específico-determinado, la aleatoriedad de recorridos, las secuencias 
temporales y narrativas, la deslocalización de los elementos o la no contigüidad entre funciones son algunos de los procesos que incrementan la capacidad de relacionamiento. En otras palabras, por medio de espacios abiertos a la individualidad y a la diversidad se intenta construir un tipo de subjetividad que combina lo individual con lo colectivo, lo local con lo global.

Por otra parte los "Patrones de equivalencia programática" proponen alteraciones sobre las jerarquías implícitas en las estructuras cohesivas de antaño. Se establecen vínculos no-jerárquicos basados en relaciones de equivalencia funcional y formal. Estos sistemas pseudo-deterministas tales como mallas, redes y campos plantean relaciones programáticas que remiten a ritmos de carácter evolutivo: intervalos, direccionalidades, seriación y secuencias. También se introducen otros distorsionantes como juegos volumétricos, cortes, choques o movimientos. Los mismos proceden del registro de fuerzas latentes en el entorno o del movimiento de los usuarios que se trasladan como vectores invisibles al proyecto arquitectónico. En estos entramados el vacío adquiere funcionalidad, el espacio no programado abandona su condición análoga para interactuar dinámicamente en la estructura.

El tensor tres, refiere a los "Espacios híbridos multiprogramados". La hibridez puede entenderse como una estrategia clave

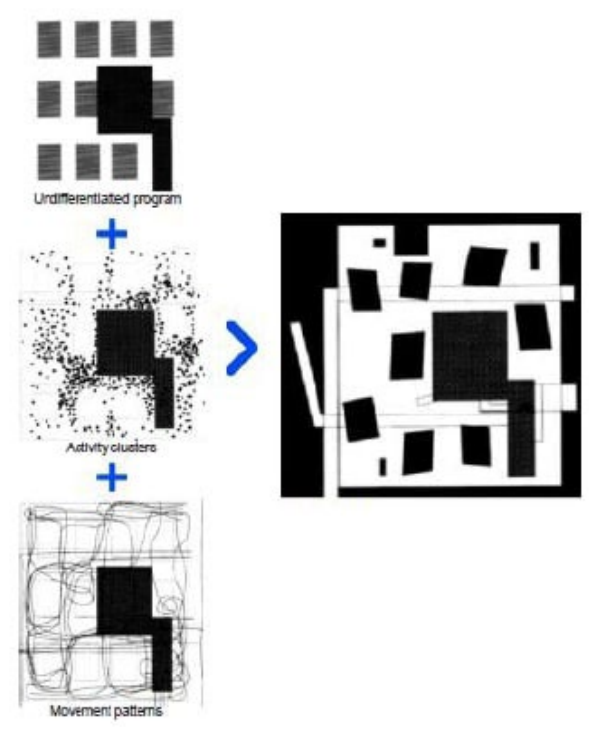

Figura 4

Museo de Arte Coreano-Americano elaborado por Stan Allen (1995).

La estructura programática surge de la superposición de una primer trama autónoma de cuadrados a la que se le superpone un nuevo campo "invisible" (trayectorias de recorridos) que desjerarquiza la estructura inicial. 

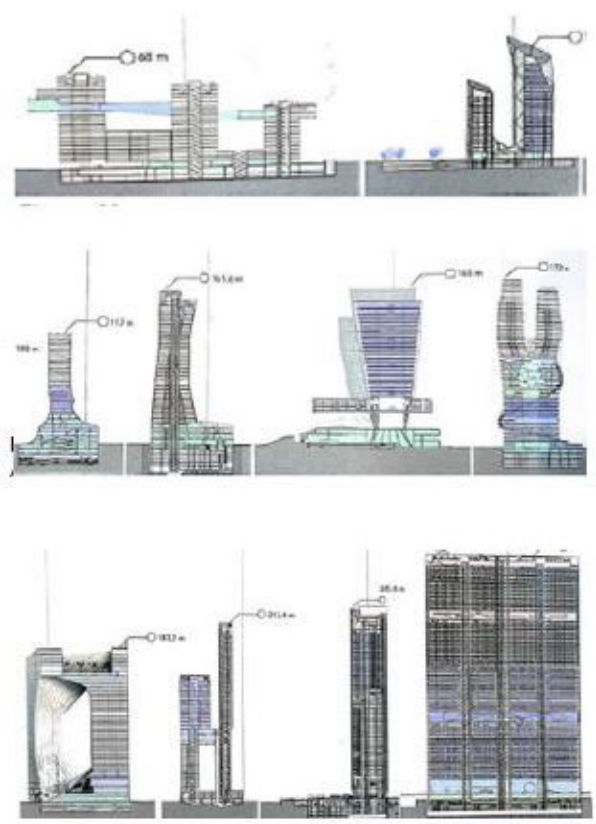

Figura 5.

La heterogeneidad de secciones y programas en altura que presentan los edificios híbridos verticales revela la diversidad morfológica que caracteriza a la producción contemporánea. Este muestreo da cuenta del tránsito del rascacielos "heterodoxo" moderno de carácter estructural al "rascacielos fatalizado" contemporáneo; indeterminado y de carácter infraestructural. para conseguir congestión y complejidad espacial. Este tipo de estrategias apelan a la superposición descohesiva de espacios y funciones. Diversos programas se integran bajo una misma estructura, sin perder especificidad. Por medio de acciones como injertos-exjertos, comensalismo-parasitismos cohabitan códigos disímiles. De hecho, los efectos volumétricos que materializan los edificios se asimilan a procesos típicos de la ciudad: desmembramiento de la masa edificatoria, plegado tridimensional, tramados de llenos y vacíos. Es decir, la fisicidad del objeto traslada la condición geográficaterritorial densa y discontinua que signa a la ciudad contemporánea.

Las formas complejas de carácter fractal son el elemento distintivo de los últimos dos tensores. La forma se concibe como el principal vehículo que impulsa la inestabilidad de las organizaciones. Esta se inserta en el proceso de diseño como un elemento anómalo capaz de generar procesos de desterritorialización funcional que dan lugar a nuevas fecundaciones "tipológicas".

“El pliegue programático”, como tipicidad formal contemporánea, se comporta como un diagrama espacial operativo que apela al "desdibujamiento" de las relaciones entre forma, función y significado. Es decir, el soporte formal no solo genera un sistema de enlace entre funciones potenciando mezclas y contaminaciones, también la acción figurativa convierte al edificio en un artefacto gráfico. La 
obra adquiere cierta identidad a través de la envolvente plegada. Se desliga de la forma de "contenedor" pasando a ser en una imagenicono.

El último tensor hace alusión a los entornos virtuales. La virtualidad plantea una realidad artificial dinámica y simulada. Estos ambientes configurados por mecanismos ilusorios se comportan como un organismo vivo definido por algoritmos. La experiencia espacial se lleva al límite, no existen restricciones de tiempo y espacio. Son entornos netamente sensoriales en los que el hombre es el principal artífice de la experiencia.

Estos últimos dos tensores serán abordados con mayor profundidad en los siguientes apartados. "Máquinas Plegadas" analiza los comportamientos sociales y formales provocados por el "El pliegue programático", correspondiente al tensor cuatro. En tanto, el penúltimo apartado “¿Un máximo de espacio y un mínimo de arquitectura?" hace alusión a las "Licuaciones programáticas en el espacio virtual" estudiadas en el último tensor. Es decir, a los procesos que por su naturaleza fisiológica dificultan reducir a los objetos en entidades formadas.

\section{"MÁQUINAS PLEGADAS"}

El vuelco trascendental que ha dado la ciencia marca un punto de inflexión en la concepción del mundo. La ciencia de la complejidad ha abierto un amplio stock de modelos y teorías que intentan explicar la complejidad del universo, tales como la teoría del caos, los sistemas auto-organizados o los fractales. Por otra parte, el comportamiento del hombre revela signos de imprevisibilidad, no linealidad y emergencia; características análogas a las que presenta la naturaleza. De alguna manera esta situación hace necesaria la "reactivación ecosófica” a la que hace alusión Guattari en el libro “Las Tres Ecologías” (1996). Dado que la diversidad es un factor inherente al ecosistema es imprescindible la comunión de los tres registros ecológicos: el medio ambiente, las relaciones sociales y la subjetividad humana. La "ecosofía” propone ampliar la dimensión del ecologismo sumándole una dimensión social y mental que estimule el cambio de pensamiento.

Entonces, frente a una idea de mundo permeado por la acción de fuerzas activas que dan movimiento a la materia y originan interacciones complejas, la arquitectura no ha quedado exenta. Se evidencia, un proceso sincrético que redefine integralmente al objeto arquitectónico. "Máquinas plegadas" hace referencia a aquellos dispositivos que presentan un grado de fluidez dérmico tal que posibilita la continua "actualización de lo virtual". No desde la representación de la realidad sino desde lo que aún está por suceder. Greg Lynn en la publicación "Folding in architecture" (1993) hace alusión a la contemporaneidad como la "edad de la curvilineidad arquitectónica". Manifiesta que el salto cualitativo, que 
diferencia a la estrategia de plegado de sus precedentes, reside en la capacidad de crear y producir vínculos en continuo con el medio.

En palabras de Eisenman los procesos maquínicos son “(...) procedimientos que desterritorializan sus elementos, sus funciones y sus relaciones de alteridad [de otro]" (Eisenman, 1997 , p. 24). Por lo tanto, lo "maquínico" se diferencia de lo mecánico por el hecho de que no se trata solamente de relaciones estructurales, implica la producción de "condiciones trópicas". Para Eisenman los sistemas de significación o en palabras de Guattari (1996) las "referencias comunicacionales" han mediado a lo largo del tiempo la relación sujeto-objeto, atribuyendo el significado como un apriorismo. Para que el significado surja del significante es necesario desarrollar nuevas formas de transferirlo que no "sepulten" a los objetos.

En el libro "El Pliegue" (1989) define al mismo como un único acto de curvatura que lleva implícito la inserción de lo material en lo espiritual. La capacidad deformativa es condición necesaria para que los dispositivos adquieran presencia ontológica. La forma se entiende como agente transformador. El estado tensado de la materia presenta un fuerte potencial desestabilizante que incide sobre la materia, el medio y el hombre. De alguna manera esta reinvención de la relación sujetoobjeto se alinea con la "reactivación ecosófica" mencionada anteriormente.
La arquitectura que caracteriza a Zaha Hadid persigue estos objetivos. Para la misma la imagen final no significa la exteriorización de un proceso de síntesis formal y conceptual. Esta emana de la propia “interioridad”, es un instante del proceso de manipulación. De esta forma podemos ver que Zaha Hadid, al igual que lo hizo Duchamp con los objetos surrealistas, atenta contra el principio de identidad de la imagen. En proyectos como el Centro de Artes Multimedia Zolhof (1993-1995) o el Centro de Heydra Aliyev (2007-2012), apela a la fragmentación de las partes y a la dislocación de la estructura como métodos compositivos. De esta forma las superficies materializan "campos de fuerza" distorsionados. La manipulación plástica permite abrir los espacios, estratificarlos, expandirlos o comprimirlos. La acción figurativa opera como el fundamento físico conceptual que impulsa trayectorias vectoriales que activan la mezcla entre funciones. Ambas esferas se solapan en un nuevo tipo de orden en el que continente y contenido se igualan.

Por lo tanto, la nueva dialéctica espacial desarticula la dicotomía de los binomios figura/fondo, interior/exterior, horizontal/ vertical. Los movimientos morfogenéticos establecen relaciones figura-figura. Deja de ser un espacio de condición abstracta capaz de ser "escaneado" por la mente y por el ojo; la capacidad de predictibilidad se complejiza. Las trayectorias híper-complejas solo alcanzan graficarse bajo determinadas condiciones de tiempo y espacio. Se producen ejemplares únicos e irrepetibles. 
Tal como explica Charles Jencks en el libro "New science $=$ New architecture" (1997) lo figural como matriz de fuerzas es un potencial en la medida que induzca cambios en la experiencia del hombre. El espacio plegado por encima de ser una estrategia semiótica, lleva implícito un cambio de paradigma.

Es un hecho que el individuo en la contemporaneidad ocupa la posición de “terminal” (Guattari, 1996) en los procesos de relacionamiento. La reinvención de la relación sujeto-cuerpo pasa por el cruce de múltiples entes autónomos que lo exceden; implica la continua sinergia entre el conjunto social, entes socioeconómicos, máquinas informáticas y naturaleza. En este sentido las mutaciones espaciales propician procesos de subjetivación necesarios para combatir la estandarización y el alineamiento, producto de la incidencia de los medios de comunicación. Permiten desocultar la intrincada red de vínculos que forjan el ecosistema. Las condiciones de desequilibrio pueden considerarse estrategias con capacidad generativa de agenciamientos individuales y colectivos necesarios para alcanzar dimensiones intrínsecamente evolutivas.

\section{¿UN MÁXIMO DE ESPACIO Y UN MÍNIMO DE ARQUITETCURA?}

No cabe duda que la incidencia de la información ha permeado los procesos de diseño generando profundas transformaciones. Esta realidad sintética y simulada por dispositivos

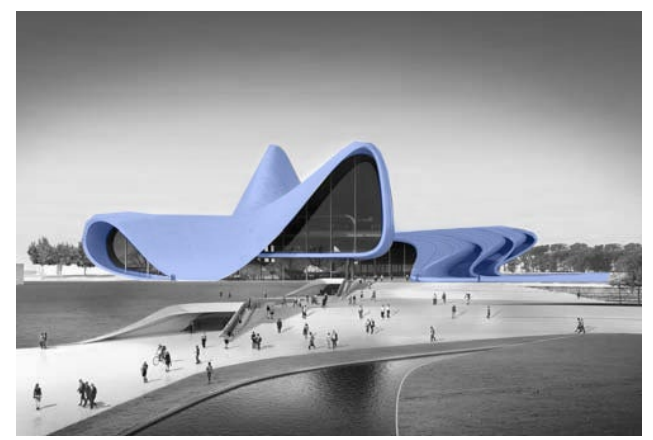

Figura 6.

En el Centro de Heydat Aliyev la manipulación plástica de la envolvente activa el paisaje circundante. Se cualifica el plano del suelo con una gran plaza pública que incorpora diversas actividades.
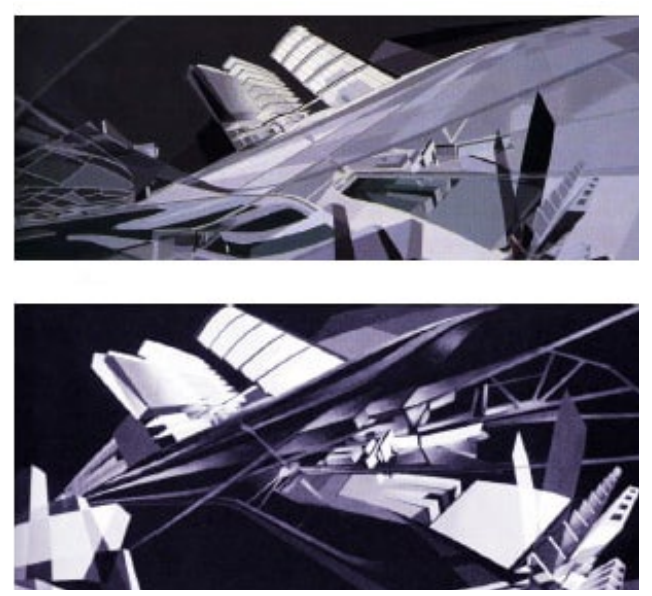

Figura 7.

La fragmentación y la composición por capas son dos mecanismos heredados del deconstructivismo que evolucionan en una nueva generación de proyectos con lógica de plegado como lo es el Centro de Arte Multimedia Zolhof. El desmontaje formal y su correlativa heterogeneidad geométrica dan la sensación de una "imagen congelada en movimiento". 


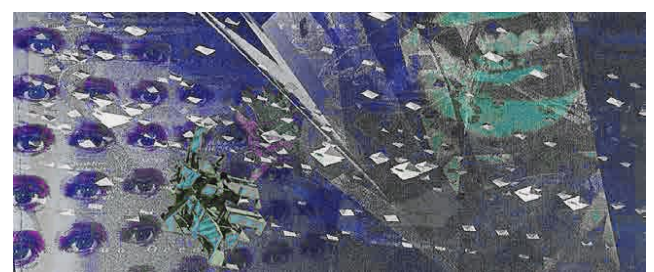

Figura 8.

Representación virtual multidimensional de Soft Babylon.

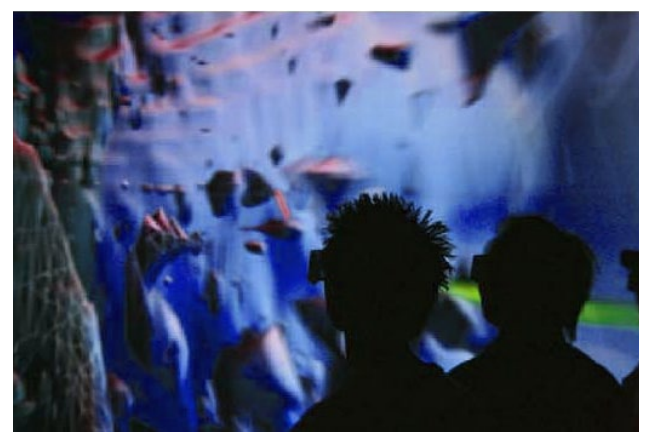

Figura 9.

Espacios de la exposición Allo-Brain. electrónicos ha generado una progresiva desmaterialización de la arquitectura. Se trata de contextos netamente sensoriales, en los que el usuario es el principal artífice.

Se habla de un nuevo estadio de la evolución humana: el "Transhumanismo". Los científicos sostienen que la tecnología podría llegar a perfeccionar la "condición humana" en todos los niveles: sociales, físicos y psicológicos. El correlato arquitectónico se vincula al concepto de "Transarquitectura”.

Un claro influyente de este término es Marcos Novak, pionero del ciberespacio. En el ensayo "Liquid Architectures in Cyberspace" (1991) postula por primera vez la idea de una "arquitectura líquida" construida íntegramente en el espacio virtual. Se trata de entornos dinámicos susceptibles a la acción de cada usuario. Los elementos se desmaterializan para alcanzar la condición de información. La "arquitectura líquida" lleva al límite la noción de espacio, se comporta como un organismo vivo definido por algoritmos. Estos entornos dinámicos, sintéticos y simulados por dispositivos electrónicos desdibujan totalmente las jerarquías implícitas. Es un espacio sin límites, que se alimenta constantemente de datos temporales, provocando fluidez espacial y temporal.

Novak retoma la ciudad utópica "New Babylon" de Constant y plantea la megaestructura como una red de vínculos generados vía internet. La 
plataforma creada en el ciberespacio no deja de crecer, formalmente es más dinámica que la original. Toda la liberación que Constant exigía para la sociedad ya es un hecho en el ciberespacio, no hay elementos físicos que marquen ningún tipo de posesión o estandarización.

En el ciberespacio el usuario es el principal artífice, provocando una interacción multiprogramática, ninguna sensación es igual a otra. El vínculo sensorial genera que la arquitectura además de estar directamente relacionada con la máquina, se vincule con otras expresiones artísticas, como la pintura y principalmente el cine. La obra pierde gravedad, comienzan a disolverse los límites horizontales y verticales.

El proyecto Allobrain@AlloSphere (2006) propone un entorno ficticio producido por la mente de los usuarios a través de impulsos nerviosos. La dinámica espacial genera la variación de figuras que cambian una vez que captan la atención de los mismos. Los arquitectos apelan a la capacidad de memoria como vínculo con el mundo exterior. Las imágenes que surgen en el espacio virtual proceden de asociaciones psíquicas y auditivas con elementos preconcebidos. De este modo, la interacción entre virtualidad y realidad propicia un espacio de nuevas situaciones, los objetos dejan de ser observados para comenzar a adquirir acción activa.
Estos espacios habitados, tanto en lo real como en lo virtual, no solo son una muestra del potencial desjerarquizante que tienen las herramientas digitales, sino que elevan al usuario a la condición de medio otorgándole visibilidad a lo invisible. Se trata de un presente continuamente re-representado; una experiencia medioambiental compleja que pone en evidencia nuestra función sensorial a través del bombardeo continúo de información.

La arquitectura adquiere carácter líquido, pudiéndose materializar totalmente en el espacio virtual, como en el caso del Guggenheim Virtual (2001) ideado por el estudio Asymptote. Aunque no se haya realizado, el objetivo del proyecto consistía en llevar a cada rincón del mundo las obras del museo. Este se podría recorrer mediante vistas tridimensionales desde el ordenador. Si bien toman como modelo el "Museo Guggenheim" de Nueva York ideado por Wright, la dinámica interior es imprevisible. Los muros pueden ser cambiados de lugar favoreciendo nuevas formas de percibir el arte. De esta manera el espacio es totalmente ilimitado, no hay galería que el visitante no pueda recorrer libremente.

En síntesis, el hiperespacio posee una estética cognitiva propia -cognitive mapping- (Castro, 1997) que opera mediante mecanismos ilusorios cuyos regímenes de temporalidad se abstienen a ser cartografiados por los sentidos. Esta visión "infinitamente móvil” se ritma por un sentido del tiempo inmediato y fragmentado, 
que genera la continua desorientación del observador. No existen visiones unívocas en estos contextos, sino multiplicidad de visiones en coexistencia. Se produce un nuevo tipo de relación. El sujeto observador se apropia aleatoriamente de la obra pasando a ser un sistema perceptivo más; un modo visual parcial y específico. Al respecto, podemos apuntar que si bien se activan resonancias inesperadas en los usuarios que denotan una realidad compleja e inclusiva, todo se reduce a pura experiencia sensorial. La "experiencia cinestética" subordina el resto de los elementos que constituyen a la obra.

\section{REFLEXIONES FINALES}

No cabe duda que la relación espacio-tiempo es un factor inherente a la configuración del espacio social de cada época. La arquitectura como receptáculo material del espacio que envuelve reverbera pensamientos simbólicos, perceptivos e imaginarios de la sociedad que los produce. La sociedad de la información se identifica con un espacio social que se configura como un denso flujo cuyos coeficientes de temporalidad tensan y deforman el mismo adquiriendo protagonismo en todas las escalas.

La externalización de los medios de comunicación a través de imágenes nos lleva a repensar las nociones de tiempo y espacio. Las imágenes adquieren rol productivo dentro de estos contextos, sus nuevas facultades insieren la redefinición de las dimensiones que constituyen al ser humano: deseos, imaginación, memoria y razón. Esta es la principal diferencia con el imaginario moderno.

Sin lugar a dudas la aceleración del tiempo desarticuló todas las categorías espaciales, el espacio se vectoriza, adquiere condición de sistema dinámico en directa relación con la "realidad fluida". De esta confrontación surgen las inflexiones que materializa la arquitectura. Variaciones operativas de incipiente carácter indisciplinado, que no guardan apriorismos formales ni legitimaciones simbólicas.

Por otra parte, la reinterpretación de la naturaleza abre al campo proyectual la posibilidad de "proyectar con genes". Por ejemplo, los comportamientos indisciplinados propios de los procesos naturales se transfieren en estrategias concretas basadas en códigos de programación que amplía el carácter evolutivo de los soportes. Dispositivos con capacidad de autoorganización que tejen vínculos virtuales no jerárquicos atribuibles a soportes tales como: mallas, redes, campos, híbridos y formas complejas.

Si la deconstrucción posmoderna fracturó el espacio en mil pedazos para poder abordarlo intrínsecamente, la contemporaneidad lo reconstruye hipotéticamente por medio de procesos experienciales. Proyectar con procesos implica trabajar con un material intangible como la experiencia sensorial o los flujos de movimiento. El espacio se plantea 


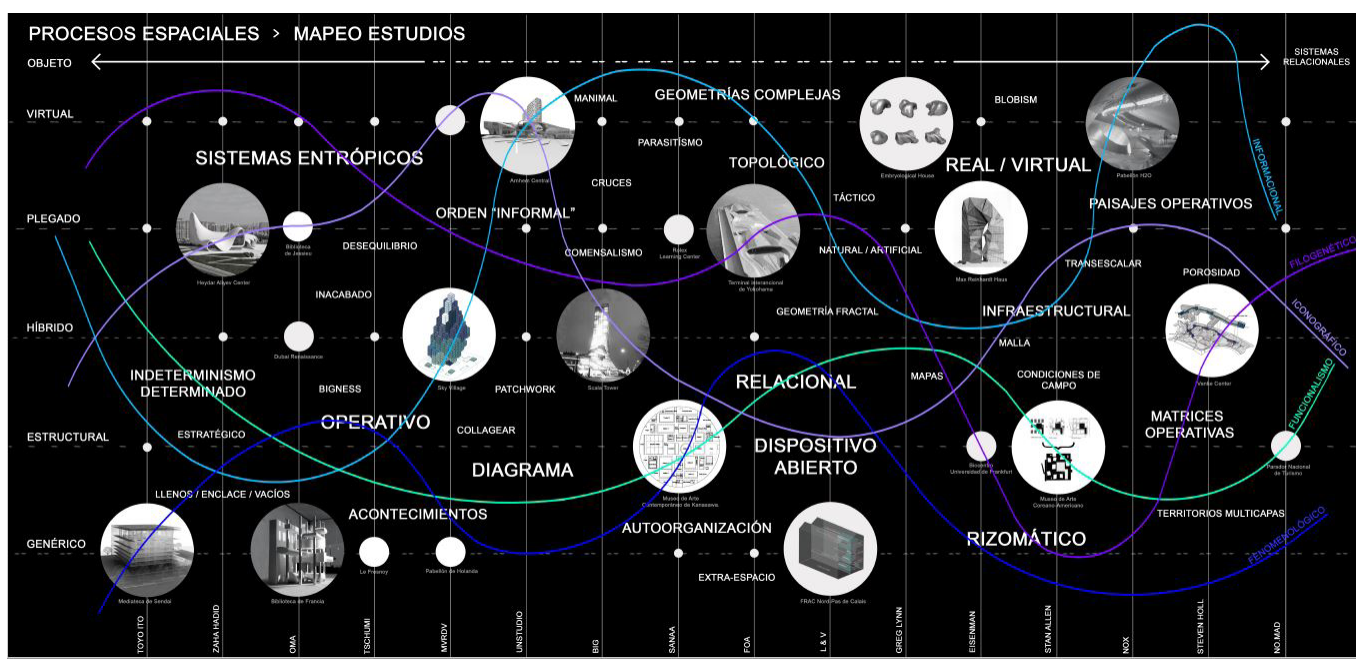

Figura 10.

Estrategias programáticas. Del alojamiento de funciones a la construcción de relaciones

El gráfico síntesis resume los procesos espaciales desarrollados a lo largo de la tesis que se corresponden con los "Cinco tensores de curvatura contemporáneos". No cabe duda que la heterogeneidad es un sello distintivo de la práctica proyectual contemporánea. De hecho muchos de los proyectos analizados remiten a estudios que integran simultáneamente distintas estrategias, esto no solo da cuenta del carácter alterno sino que también es un indicio del desplazamiento hacia lo espacial que nos planteamos como hipótesis de partida.

como una secuencia temporal narrativa con efectos visuales y flujos temporales que se mapifican a través de estrategias sintácticofigurativas. Organizaciones transitorias, o en palabras de Bernard Tschumi (1996) "situaciones momento", capaces de favorecer instantes azarosos. Podemos decir entonces que es el libre albedrío el que le otorga al hombre presencia en el espacio.

Se trata de posturas "maquínicas" que resitúan al hombre en el espacio. Asistimos a un proceso de "espacialización" del sujeto a través de las fuerzas psíquicas que ejercen estos entornos permeados por la tecnología. La percepción escapa lo meramente fisiológico, el espacio se experimenta imaginariamente. Recorrido y visión se dislocan, siguen caminos paralelos que pueden o no solaparse (Lorenzo-Eiroa, 2013).

Estas condiciones se ven aún más exacerbadas dentro de los entornos virtuales altamente tecnificados. Todo se reduce a pura experiencia perceptiva, llegando en algunos casos a perderse totalmente la fisicidad y el sentido de ubicuidad del objeto. Tal como vaticinaba Marshall McLuhan en 1970 los medios de comunicación representan "prolongaciones del hombre”. Dentro de estos ambientes, el hombre 
es un aparato perceptivo más. El sujeto virtual se desenvuelve gracias a las funciones adquiridas: la memoria instantánea y la capacidad de síntesis de imágenes reales y virtuales. De esta forma, el espacio se infiltra en la interioridad del ser, se construye y reconstruye en la mente del usuario.

El proceso de gradación espacial transitado hasta aquí refleja que el hombre contemporáneo se reconoce en un tipo de espacialidad que excede la dimensión material. Involucra por sobre todas las cosas una dimensión mental. Un ambiente en el cual la memoria y la imaginación pueden desplegarse libremente. Esta podría ser la curvatura que signa la contemporaneidad.

El conjunto de "acontecimientos tensados" y las causas que sustentan este giro conceptual y material evidencian la emergencia de nuevos modelos críticos capaces de adaptarse a las lógicas complejas del mundo contemporáneo.

Estos desplazamientos topológicos revelan relaciones disruptivas, desarticuladas, contradictorias, híbridas y complejas. En definitiva esta lectura direccionada a comprender ciertas lógicas busca expandir los límites de lo disciplinar, instaurar una actitud crítica necesaria para repensar la arquitectura contemporánea. Lejos de establecer modelos absolutos, estos desplazamientos intrínsecamente evolutivos significan posibles vías de proyección hacia futuros escenarios. BIBLIOGRAFÍA

\section{BIBLIOGRAFÍA}

ÁBALOS, I. \& HERREROS, J. (2010). Una nueva naturalidad (7 micromanifiestos). En Gausa, M. \& Devesa, R. (eds.) Otra mirada, posiciones contra crónicas. La acción crítica como reactivo en la arquitectura española reciente. (p.253-258). Barcelona, España: Gustavo Gili.

ÁBALOS, I. (2010). La belleza del siglo XXI. En Gausa, M. \& Devesa, R. (eds.) Otra mirada, posiciones contra crónicas. La acción crítica como reactivo en la arquitectura española reciente. (p.171-176). Barcelona, España: Gustavo Gili.

ALEXANDER, C. (1968). La ciudad no es un árbol. Cuadernos Summa - Nueva Visón, 9, 20-30.

ALEXANDER, C. (1976). Ensayo sobre la sintesis de la forma (4th ed.). Buenos Aires, Argentina: Infinito.

ALLEN, S. (2009). Practice: Achitecture technique + representation ( $2^{\mathrm{a}}$ ed.). Abingdon, Inglaterra: Routledge.

BAUDRILLARD, B. (1995). El sistema de los objetos $\left(14^{a}\right.$ ed.). Coyoacán, México: Siglo XXI.

Bauman, Z. (2002). Modernidad líquida ( $2^{\mathrm{a}}$ ed.). Buenos Aires, Argentina: FCE.

BERTOLA, R. (2013). El diagrama arquitectónico después de Deleuze: estudio de casos de holandeses (Tesis Doctoral). Universidad Politécnica de Cataluña, Barcelona, España. Accedido el 3 de diciembre, 2018, desde https:// upcommons.upc.edu/handle/2117/95607 
CASTRO NOGUEIRA, L. (1997). La risa del espacio. El imaginario espacio-temporal en la cultura contemporánea, una reflexión sociológica. (1 $1^{\mathrm{a}}$ ed.). Madrid, España: Tecnos.

CIFUENTES, C. (s.f). Narrativas cibernéticas y arquitectura computacional (Tesis de Doctoral). Universidad Politécnica de Cataluña, BarceIona, España. Accedido el 17 de diciembre, 2018, desde https://www.researchgate.net/ publication/301553542_Narrativas_ciberneticas_y_ arquitectura_computacional_Cybernetic_narratives_and_computational_architecture

DELEUZE, G. \& GUATTARI, F. (1976). Rizoma (1 ${ }^{\mathrm{a}}$ ed.). Valencia, España: Pre-Textos.

DELEUZE, G. \& GUATTARI, F. (2002). Mil mesetas. Capitalismo y esquizofrenia ( $5^{\mathrm{a}} \mathrm{ed}$.). Valencia, España: Pre-Textos.

Deleuze, G. (1989). El pliegue (1 $1^{\mathrm{a}}$ ed.). Barcelona, España: Paidós.

DÍAZ MORENO, C. \& GARCÍA GRINDA, E. (2004). Campos de juegos líquidos, fragmentos de una conversación. El Croquis, 121/122, 9-25.

EISENMAN, P. (2011). Diez edificios canónicos

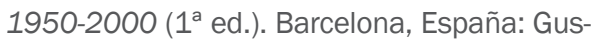
tavo Gili.

FERNANDEZ PER, A., MOZAS, J. \& ARPA, J. (2011). This is Hybrid: an analysis of mixeduse building by $a+t$ ( $1^{a}$ ed.). Vitoria-Gasteiz, España: $\mathrm{a}+\mathrm{t}$.

GARCÍA GONZÁLEZ, C. (2014). Atlas de Exodus (Tesis Doctoral). Universidad Politécnica de Madrid, España. Accedido el 8 de agosto, 2018, desde http://oa.upm.es/30888/1/ CARLOS_GARCIA_GONZALEZ.pdf
GARCÍA-GERMAN, J. (2012). Estrategias operativas en arquitectura. Técnicas de proyecto de Price a Koolhaas. (1 ${ }^{a}$ ed.). Buenos Aires, Argentina: Nobuko.

GAUSA, M. \& DEVESA, R. (eds.) (2010). Otra mirada, posiciones contra crónicas. La acción crítica como reactivo en la arquitectura española reciente. ( $1^{a}$ ed.). Barcelona, España: Gustavo Gili.

GAUSA, M. (2010). Open, espacio, tiempo, información. Arquitectura, vivienda y ciudad contemporánea. Teoría e historia de un cambio (1 $1^{\mathrm{a}}$ ed.). Barcelona, España: Actar.

GAUSA, M. (2010). Tiempo dinámico/orden (in) fromal: trayectorias (in)disciplinadas. En Gausa, M. \& Devesa, R. (eds.) Otra mirada, posiciones contra crónicas. La acción crítica como reactivo en la arquitectura española reciente. (p.217-224). Barcelona, España: Gustavo Gili.

GAUSA, M., GUALLART, V., MULLER, W., MORALES, J., PORRAS, F. \& SORIANO, F. (2001). Diccionario Metápolis de la arquitectura avanzada (1 $1^{a}$ ed.). Barcelona, España: Actar.

GIMÉNEZ, C., MIRÁS, M. \& VALENTINO, J. (2011). La arquitectura cómplice, teorías de la arquitectura en la contemporaneidad ( $1^{\mathrm{a}} \mathrm{ed}$.). Buenos Aire, Argentina: Nobuko.

GUATTARI, F. (1996). Las tres ecologías (2 ${ }^{\mathrm{a}}$ ed.). Valencia, España

HEIDEGGER, M. (1951). Costruir, habitar, pensar. Accedido el 2 de febrero, 2019, desde http:// www.fadu.edu.uy/estetica-diseno-ii/ files/2013/05/Heidegger-Construir-Habitar-Pensar1.pdf 
JENCKS, C. (1997). New Science = New Architecture. ( $1^{\mathrm{a}}$ ed.). Londres, Inglaterra: Wiley-Academy.

KOOLHAAS, R. \& MAU, B. (1997). S, M, L, XL (1 ${ }^{\mathrm{a}}$ ed.). Colonia, Alemania: Tashen.

KOOLHAAS, R. (1978). Delirio de Nueva York, un manifiesto retroactivo para Manhattan ( $1^{a}$ ed.). Barcelona, España: Gustavo Gili.

LANDA, M. (2011). Mil años de historia no lineal ( $1^{\text {a }}$ ed.). Barcelona, España: Gedisa.

LORENZO-EIROA, P. (2013). Superposición posthistórica: redefiniendo el rol de lo relativo. Plot, 13, 165-171.

LYNN, G. (1993). Folding architecture (1 ${ }^{a}$ ed.). Londres, Inglaterra: Architectural Design.

MORALES, J. (2010). Adiós a la metáfora. Manipulaciones de la realidad. En Gausa, M. \& Devesa, R. (eds.) Otra mirada, posiciones contra crónicas. La acción crítica como reactivo en la arquitectura española reciente. (p.51-62). Barcelona, España: Gustavo Gili.

MORALES, J. (2010). Asociar, superponer, conectar. En Gausa, M. \& Devesa, R. (eds.) Otra mirada, posiciones contra crónicas. La acción crítica como reactivo en la arquitectura española reciente. (p.47-50). Barcelona, España: Gustavo Gili.

NOVAK, M. (1991). Liquid Architectures in Cyberspace. Accedido el 7 de diciembre, 2018, desde https://www.evl.uic.edu/datsoupi/ coding/readings/1991_Novak_Liquid.pdf? fbclid=IwAROtsA5wQaOXhI2EKf1Y5KiOMeka-G9J_Qk_TLqhl15_sSjChSKgK9yTh7o
ROWE, C. \& KOETTER, F. (1998). Ciudad collage ( $2^{\mathrm{a}}$ ed.). Barcelona, España: Gustavo Gili.

STAN A (1999), Practice vs Project. Praxis: Journal of Writing + Building Vol 1 No 0, 112-125

TSCHUMI, B. (1996). Architecture and disjunction ( $2^{\mathrm{a}}$ ed.). Cambridge, Inglaterra: MIT.

TSCHUMI, B. \& CHENG, I (ed.) (2003). The state or architecture at the beginning of the 21st century ( $1^{\mathrm{a}}$ ed.). Nueva York, Estados Unidos: Monacelli, Columbia University.

ZELLNER, P. (1999). Hybrid space, new forms in digital architecture. ( $1^{\mathrm{a}}$ ed.). Londres, Inglaterra: Thames 